\title{
Assessing and Comparing Mental Skills of Men Players' Positions in Volleyball Premier League Team of Iran
}

\author{
Mostafa Chavoshian ${ }^{1}$, Saeid Soukhtehzari², Hooman Angoorani ${ }^{3}$, Mina Rezaei ${ }^{4}$, Sayyah Mansour ${ }^{5 *}$ \\ ${ }^{1}$ Master of Exercise Sciences and Physical Education, Kashan, I.R. Iran \\ 2Shahid Beheshti University of Medical Sciences, Tehran, I.R. Iran \\ ${ }^{3}$ Department of Sports and Exercise Medicine, HazratRasool-e-Akram Hospital, Iran University of Medical Sciences, Tehran, Iran \\ ${ }^{4}$ Master Student of Exercise Physiology, Imam Khomeini International University \\ ${ }^{5}$ Exercise Science and Physical education, Associate Professor, Affiliated Faculty Member of Trauma Research Center, Kashan University of Medical Sciences. Kashan, Iran
}

\begin{abstract}
Mental skills are important aspects of successful sport performance in all sport competitions. This study was designed to assess and compare the mental skills of men players' positions in premier league volleyball team in year 2015. This cross sectional research includes 69 Iran men's premier league volleyball team players in year 2015 who participated in the premier league competitions in year 2015. Mental skills as well as demographic data of the players was assessed by OMSAT-3 questioner and a personal data form. One-way ANOVA was employed to analyze the data. The result of analysis indicated that there was no significant differences between the main components of fundamental $(p=0.21)$, psychosomatic $(p=0.12)$, and cognitive skills $(p=0.584)$ of different positions of the volleyball players. However, there was a significant difference between the sub skills of reaction to stress (0.002) and fear control (0.020) of different positions of volleyball players. Outside hitters and opposite hitter were significantly weaker than the setters, libero and middle blocker in fear control $(p<0.05)$ and reaction to stress $(p<0.05)$. Given the importance of mental skills in the achievement of volleyball players, focusing on improving the mental skills of the mentioned positions in volleyball especially in outside hitters and opposite hitter is highly recommended.
\end{abstract}

Keywords: Mental skills, premier league, volleyball, positions

\section{INTRODUCTION}

High level sport competition requires physical readiness plus sport skills; however, such conditions are no guarantee for success unless the athlete is mentally prepared as well. According to the research literature, having optimal mental skills could result in improved

\footnotetext{
*Correspondence: mansorsayyahagmail.com

Sayyah Mansour PhD, Exercise Science and Physical education, Associate Professor, Affiliated Faculty Member of Trauma Research Center, Kashan University of Medical Sciences. Kashan, IRAN. Phone: 989121946743
}

Received: 13 February 2018 Accepted: 26 February 2018

\section{Sleep and Hypnosis \\ Journal homepage: \\ www.sleepandhypnosis.org \\ ISSN: 2458-9101 (Online)}

status of psychomotor performance especially attention which mostly affects the sporting performance (Taheri \& Irandoust, 2017). The significance of mental skill as a contributing factor to the success of athletes is well acknowledged by the sport psychologists, trainers and nearly most of the people involved in athlete training. On the other hand, being aware of the mental skills status in athletes can provide the good feedback for coaches, which cause mental balance and improve the athletes' focus leading to strong athletic performance (Irandoust, Taheri, Neto, \& Lotfi, 2017). For this reason, many sport organizations have professional trainers trained in sport psychology to prepare their athletes. There are abundance of research findings to support the significance of mental skills as an important predictors of success in 
sport performance (Bahmani, Soukhtehzari, Mazaherinezhad, \& Sayyah, 2015; Ebben \& Gagnon, 2012; Güler \& Erhan, 2017; Kruger, 2010; MacNamara, Button, \& Collins, 2010; Morris, 2000; Paquette \& Sullivan, 2012; Sheard \& Golby, 2006; Znazen et al., 2016), therefore, the research was conducted to assess the mental skills of men players' positions in volleyball premier league team of Iran and comparing these skills among different positions.

\section{MATERIAL AND METHODS}

The mental skill of the volleyball players participating in the major league of Iran was assessed by using OMSAT-
III. The instrument measures 12 sub skills of Goal Setting, Self Confidence, Commitment, Stress Reactions, Fear Control, Activation, Relaxation, Imagery, Mental Practice, Concentration, Reconcentration and Competition planning rated on 6-point Likert scale answered as "strongly disagree" scored 1 to "strongly agree" scored 7. The OMSAT-3's scales has internal consistency ( $\alpha=.68$ to 0.88 , mean 0.78 ) and temporal stability ( $r=.78$ to 0.96 , mean 0.86) (Durand-Bush, Salmela, \& Green-Demers, 2001). The data were collected at the competition sites during the games. Sixty nine players from different positions were selected proportional to the number of positions in the game, that is, less libero and midfield defenders compared to the attackers. Statistical analysis

Table 1. One-way ANOVA test of comparing mental sub skills of players positions

\begin{tabular}{|c|c|c|c|c|c|c|}
\hline & & Sum of Squares & df & Mean Square & $\mathbf{F}$ & Sig. \\
\hline \multirow{3}{*}{ Goal setting } & Between Groups & 49.223 & 4 & 12.306 & 1.885 & 0.124 \\
\hline & Within Groups & 417.763 & 64 & 6.528 & & \\
\hline & Total & 466.986 & 68 & & & \\
\hline \multirow{3}{*}{ Self-confidence } & Between Groups & 4.054 & 4 & 1.013 & .146 & 0.964 \\
\hline & Within Groups & 444.555 & 64 & 6.946 & & \\
\hline & Total & 448.609 & 68 & & & \\
\hline \multirow{3}{*}{ committment } & Between Groups & 61.957 & 4 & 15.489 & 2.038 & 0.10 \\
\hline & Within Groups & 486.477 & 64 & 7.601 & & \\
\hline & Total & 548.435 & 68 & & & \\
\hline \multirow{3}{*}{ Stress reaction } & Between Groups & 163.608 & 4 & 40.902 & 4.927 & $0.002^{\dagger}$ \\
\hline & Within Groups & 531.348 & 64 & 8.302 & & \\
\hline & Total & 694.957 & 68 & & & \\
\hline \multirow{3}{*}{ Relaxation } & Between Groups & 42.665 & 4 & 10.666 & .728 & 0.576 \\
\hline & Within Groups & 937.074 & 64 & 14.642 & & \\
\hline & Total & 979.739 & 68 & & & \\
\hline \multirow{3}{*}{ Fear control } & Between Groups & 118.556 & 4 & 29.639 & 3.159 & $0.020^{\dagger}$ \\
\hline & Within Groups & 600.430 & 64 & 9.382 & & \\
\hline & Total & 718.986 & 68 & & & \\
\hline \multirow{3}{*}{ Energizing } & Between Groups & 58.099 & 4 & 14.525 & 1.276 & 0.289 \\
\hline & Within Groups & 728.509 & 64 & 11.383 & & \\
\hline & Total & 786.609 & 68 & & & \\
\hline \multirow{3}{*}{ concentration } & Between Groups & 6.008 & 4 & 1.502 & .084 & 0.987 \\
\hline & Within Groups & 1140.804 & 64 & 17.825 & & \\
\hline & Total & 1146.812 & 68 & & & \\
\hline \multirow{3}{*}{ reconcentration } & Between Groups & 94.594 & 4 & 23.649 & .758 & 0.556 \\
\hline & Within Groups & 1996.391 & 64 & 31.194 & & \\
\hline & Total & 2090.986 & 68 & & & \\
\hline \multirow{3}{*}{ Imagery } & Between Groups & 32.296 & 4 & 8.074 & 1.554 & 0.197 \\
\hline & Within Groups & 332.516 & 64 & 5.196 & & \\
\hline & Total & 364.812 & 68 & & & \\
\hline \multirow{3}{*}{ Mental practice } & Between Groups & 23.350 & 4 & 5.837 & .653 & 0.627 \\
\hline & Within Groups & 571.722 & 64 & 8.933 & & \\
\hline & Total & 595.072 & 68 & & & \\
\hline
\end{tabular}

${ }^{\dagger}$ significant at 0.05 
including Analysis of variance test (ANOVA) and LSD post hoc tests was performed on data by using SPSS: PC 16.0.

\section{RESULTS}

The result of analysis showed that there were 9 (13\%) setters, 19 (27.5\%) oppositions, 11 (15.9\%) outside hitters, 11 (15.9\%) liberos and 19 (27.5\%) midfield blockers.

Further analysis was performed on data by applying one-way analysis of variance (ANOVA) to compare the mental sub skills of volleyball players based on their positions. The result of analysis revealed that here were significant differences among the different play positions on reaction to stress and fear control $(P=0.002, P=0.020)$. These results are presented in table 1 .

LSD post hoc test was used to determine the sources of differences. The result indicated that there were significant differences between the setter and liberos compared to other positions in stress reaction $(P=0.000$, $\mathrm{P}=0.025, \mathrm{P}=0.038$ ). The setters and liberos scored higher

Table 2. LSD post hoc test comparing players positions in stress reaction and fear control mental skills

\begin{tabular}{|c|c|c|c|}
\hline Dependent Variable & (I) post & (J) post & Sig. \\
\hline \multirow{20}{*}{ Stress reaction } & \multirow{4}{*}{ Setter } & Opposition & 0.001 \\
\hline & & Outside Hitter & 0.025 \\
\hline & & Libero & 0.636 \\
\hline & & Middle Blocker & 0.038 \\
\hline & \multirow{4}{*}{ Opposition } & Setter & 0.000 \\
\hline & & Outside Hitter & 0.210 \\
\hline & & Libero & 0.001 \\
\hline & & Middle Blocker & 0.047 \\
\hline & \multirow{4}{*}{ Outside hitter } & Setter & 0.025 \\
\hline & & Opposition & 0.210 \\
\hline & & Libero & 0.059 \\
\hline & & Middle Blocker & 0.641 \\
\hline & \multirow{4}{*}{ Libero } & Setter & 0.636 \\
\hline & & Opposition & 0.001 \\
\hline & & Outside Hitter & 0.059 \\
\hline & & Middle Blocker & 0.095 \\
\hline & \multirow{4}{*}{ Middle Blocker } & Setter & 0.038 \\
\hline & & Opposition & 0.047 \\
\hline & & Outside Hitter & 0.641 \\
\hline & & Libero & 0.095 \\
\hline \multirow{20}{*}{ Fear control } & \multirow{4}{*}{ Setter } & Opposition & 0.012 \\
\hline & & Outside Hitter & 0.046 \\
\hline & & Libero & 0.936 \\
\hline & & Middle Blocker & 0.104 \\
\hline & \multirow{4}{*}{ Opposition } & Setter & 0.012 \\
\hline & & Outside Hitter & 0.727 \\
\hline & & Libero & 0.006 \\
\hline & & Middle Blocker & 0.248 \\
\hline & \multirow{4}{*}{ Outside Hitter } & Setter & 0.046 \\
\hline & & Opposition & 0.727 \\
\hline & & Libero & 0.029 \\
\hline & & Middle Blocker & 0.520 \\
\hline & \multirow{4}{*}{ Libero } & Setter & 0.936 \\
\hline & & Opposition & 0.006 \\
\hline & & Outside Hitter & 0.029 \\
\hline & & Middle Blocker & 0.068 \\
\hline & \multirow{4}{*}{ Middle Blocker } & Setter & 0.104 \\
\hline & & Opposition & 0.248 \\
\hline & & Outside Hitter & 0.520 \\
\hline & & Libero & 0.068 \\
\hline
\end{tabular}

*. The mean difference is significant at the 0.05 level. 
in stress reaction than other positions. The result also showed that there were significant differences between the setter and liberos and opposition compared to outside hitters and oppositions in fear control $(P=0.012$, $P=0.046$ ). The setters and liberos scored higher in stress reaction than other positions. These results are presented in table 2.

In addition, one-way ANOVA was used to compare the fundamental, psychosomatic, and cognitive components of mental skills of different positions. The result showed that there was no significant differences among these component based on positions $(p>0.05)$. These results are presented in table 3 .
Additional analysis was performed by paired t-test to compare the subcomponents of fundamental, psychosomatic and cognitive mental skills based on the players' positions. The result of analysis indicated that there was significant difference between the subcomponents of fundamental versus psychosomatic $(P=0.001)$, fundamental versus cognitive $(P=0.001)$ and psychosomatic versus cognitive $(P=0.001)$. The fundamental components of mental skill were significantly higher than the psychosomatic and cognitive components. Also, the cognitive components of mental skill were significantly higher than the psychosomatic components. These results are presented in table 4, 5 and 6.

Table 3. One-way ANOVA table comparing fundamental, psychosomatic and cognitive components of players' positions

\begin{tabular}{|c|c|c|c|c|c|c|}
\hline & & Sum of Squares & df & Mean Square & $\mathbf{F}$ & Sig. \\
\hline \multirow{3}{*}{ Fundamental } & Between Groups & 1.323 & 4 & .331 & 1.478 & .219 \\
\hline & Within Groups & 14.322 & 64 & .224 & & \\
\hline & Total & 15.646 & 68 & & & \\
\hline \multirow{3}{*}{ psychosomatic } & Between Groups & 1.676 & 4 & .419 & 1.870 & .127 \\
\hline & Within Groups & 14.344 & 64 & .224 & & \\
\hline & Total & 16.020 & 68 & & & \\
\hline \multirow{3}{*}{ Cognitive } & Between Groups & 1.071 & 4 & .268 & 1.300 & .279 \\
\hline & Within Groups & 13.178 & 64 & .206 & & \\
\hline & Total & 14.249 & 68 & & & \\
\hline
\end{tabular}

Table 4. Comparing fundamental versus psychosomatic Skills of different positions

\begin{tabular}{clccc}
\hline Post & Mental Skill Components & t & df & Sig. (2-tailed) \\
\hline Setter & fundamental - psychosomatic & 8.175 & 8 & 0.001 \\
Opposition & fundamental - psychosomatic & 22.150 & 18 & 0.001 \\
Outside Hitter & fundamental - psychosomatic & 11.405 & 10 & 0.001 \\
Libero & fundamental - psychosomatic & 8.977 & 10 & 0.001 \\
Middle Blocker & fundamental - psychosomatic & 16.615 & 18 & 0.001 \\
\hline
\end{tabular}

Table 5. Comparing fundamental versus cognitive skills of different positions

\begin{tabular}{clccc}
\hline Post & Mental Skill Components & $\mathbf{t}$ & df & Sig. (2-tailed) \\
\hline Setter & fundamental - cognitive & 7.718 & 8 & 0.001 \\
Opposition & fundamental - cognitive & 16.066 & 18 & 0.001 \\
Outside Hitter & fundamental - cognitive & 9.746 & 10 & 0.001 \\
Libero & fundamental - cognitive & 10.851 & 10 & 0.001 \\
Middle Blocker & fundamental - cognitive & 15.493 & 18 & 0.001 \\
\hline
\end{tabular}

Table 6. Comparing psychosomatic versus cognitive skills of different positions

\begin{tabular}{|c|c|c|c|c|}
\hline Post & Mental Skill Components & $\mathbf{t}$ & df & Sig. (2-tailed) \\
\hline Setter & psychosomatic - cognitive & -1.619 & 8 & 0.144 \\
\hline Opposition & psychosomatic - cognitive & -6.153 & 18 & 0.001 \\
\hline Outside Hitter & psychosomatic - cognitive & -1.760 & 10 & 0.109 \\
\hline Libero & psychosomatic - cognitive & -.988 & 10 & 0.346 \\
\hline Middle Blocker & psychosomatic - cognitive & -4.381 & 18 & 0.001 \\
\hline
\end{tabular}




\section{DISCUSSION AND CONCLUSION}

This study was conducted to assess the mental skills of volleyball players in major league of volleyball in Iran according to their playing position and secondly to compare these skills based on the players position. These skills were assessed by using OMSAT-III; an instrument that has international reputation and has been validated by different researches. The result of analysis indicated that there were not any significant differences among the mental subskills of different positions of players except the subskills of reaction to stress and fear control of different positions of men volleyball players in major league of volleyball in Iran. The setters and liberoes were in a better condition compared to other positions in these two subskills. These results are similar to that of findings of Mostafa, et al. (2016) who examined the mental subskills of junior men national volleyball team of Iran (Mostafa \& Mansour, 2016). A visual inspection of scores reveals that the players scored very poorly on subskills of psychosomatic and cognitive components. For that reason, additional analysis was performed to compare fundamental, psychosomatic, and cognitive subcomponents of mental skills of volleyball players. The results indicated that the players were significantly in a higher level the fundamental than psychosomatic or cognitive components. This type of contrast has not been performed in previous research (Güler \& Erhan, 2017) when using OMSAT-III. It seem like the subskills of goalsetting, self-confidence and commitment develop throughout the years of playing experience, however, such condition were not observed in psychosomatic and cognitive components. Goal setting is an important aspect of behavior that influences the motivation and by directing the attention and actions; it improves performance. Goal setting theory was initially developed in organizational psychology by Locke and Latham (1994) to describe achievement behaviors in industry settings (Locke \& Latham, 1994). Bueno (2008) claimed that goal setting is one of the most effective psychological strategies for improving performance and motivation in organizational settings (Bueno, Weinberg, Fernández-
Castro, \& Capdevila, 2008). When an individual define goals, it is likely to set different categories of goals including hard, moderate, or easy goals (Guelmami, Hamrouni, Agr, \& ebi, 2014). Hard goals require very hard efforts and are achievable with great difficulty; in most cases may lead to failure and frustration. Goal setting may be a function of athletes' experience. They learn through years of experience to set goals that are realistic based on their ability, thus result in success in most circumstances. On the contrary, easy goals are achievable easily, without need of extreme effort. Moderately difficult goals have some difficulty. Moderately difficult goals are challenging, but achievable (Jia and Dong, 2006). The result of this study showed that the volleyball players were relatively skillful in goal setting compared to other subskills. Self-confidence is another important subscale of mental skill and is associated with self-efficacy (Bandura, 1997). Self-efficacy is a specific form of selfperception, it is about the perceived ability one feels about a specific situation to confront a task (Hagan, Pollmann, \& Schack, 2017) and has inverse relationship with anxiety (Birrer \& Morgan, 2010).

The volleyball players of major league showed low scores on other subscale of mental skills including relaxation, concentration, and reconcentration, fear control, energizing, imagery, competition plan and mental practice. Williams and Krane (2001) has identified a number of psychological characteristics of highly successful athletes (Olympians) including well-developed competition plans, well-developed coping strategies, and pre-competitive mental preparation (Williams \& Krane, 2001). Gould et al., (2002) also showed that psychological skills differentiate between successful and unsuccessful athletes (Gould, Dieffenbach, \& Moffett, 2002). The result of this study showed that the players in major league volleyball competitions lacked some of the important mental subskills. It was concluded that contrary to the fundamental mental skills that may improve to some extent as a result of playing experience in the game, psychosomatic and cognitive mental skills require specific training and they develop only through specific training program. 
Acknowledgement: The researchers wish to express his appreciation to the sincere cooperation of the volleyball players who completed the questioners.

Conflict of interest: The authors declare no conflict of interest.

\section{References}

Bahmani, B., Soukhtehzari, S., Mazaherinezhad, A., \& Sayyah, M. (2015). Assessing mental skills of student athletes in a colligate sport olympiad. Biosciences Biotechnology Research Asia, 12, 527-531.

Bandura, A. (1997). Self-efficacy: The exercise of control: Macmillan.

Birrer, D., \& Morgan, G. (2010). Psychological skills training as a way to enhance an athlete's performance in high-intensity sports. Scand J Med Sci Sports, 20 Suppl 2, 78-87. doi:10.1111/ j.1600-0838.2010.01188.x

Bueno, J., Weinberg, R. S., Fernández-Castro, J., \& Capdevila, L. (2008). Emotional and motivational mechanisms mediating the influence of goal setting on endurance athletes' performance. Psychology of Sport and Exercise, 9(6), 786-799.

Durand-Bush, N., Salmela, J. H., \& Green-Demers, I. (2001). The Ottawa mental skills assessment tool (OMSAT-3*). The Sport Psychologist, 15(1), 1-19.

Ebben, W. P., \& Gagnon, J. (2012). The Relationship Between Mental Skills, Experience, and Stock Car Racing Performance. Journal of Exercise Physiology Online, 15(3).

Gould, D., Dieffenbach, K., \& Moffett, A. (2002). Psychological characteristics and their development in Olympic champions. Journal of applied sport psychology, 14(3), 172-204.

Guelmami, N., Hamrouni, S., Agr, \& ebi, B. (2014). Psychological profiles of talented male youth athletes in team sports games. Journal of Physical Education and Sport Management, 5(1), 5-10.

Güler, M. Ş., \& Erhan, S. E. (2017). THE EVALUATION OF MENTAL ABILITIES OF ATHLETES IN DIFFERENT BRANCHES. European Journal of Physical Education and Sport Science.

Hagan, J. E., Jr., Pollmann, D., \& Schack, T. (2017). Elite Athletes' In-event Competitive Anxiety Responses and Psychological Skills Usage under Differing Conditions. Front Psychol, 8, 2280. doi:10.3389/fpsyg.2017.02280

Irandoust, K., Taheri, M., Neto, G. R., \& Lotfi, L. (2017). Physical and Physiological Literacy Feedback Improves the Exercise Behavior in TOFI Governors and Chief Executive Officers.
Informed consent: Informed consent was obtained from all the participants included in the study.

Funding: The authors declare that the current study was not financially supported by any institution or organization.

Kruger, A. (2010). Sport psychological skills that discriminate between successful and less successful female university field hockey players, African Journal for Physical, Health Education, Recreation and Dance, 16 (2) June 2010: pp. 240-250: errata. African Journal for Physical Health Education, Recreation and Dance, 16(3), 1

Locke, E., \& Latham, G. (1994). Goal-setting theory. Organizational Behavior 1: Essential Theories of Motivation and Leadership, 159-183.

MacNamara, Á., Button, A., \& Collins, D. (2010). The role of psychological characteristics in facilitating the pathway to elite performance part 1: Identifying mental skills and behaviors. The sport psychologist, 24(1), 52-73.

Morris, T. (2000). Psychological characteristics and talent identification in soccer. Journal of sports sciences, 18(9), 715726.

Mostafa, C., \& Mansour, S. (2016). ASSESSING AND COMPARING PLAYERS POSITIONS MENTAL SKILLS OF IRAN MEN'S NATIONAL JUNIOR VOLLEYBALL TEAM. IIOAB JOURNAL, 7 34-39.

Paquette, K. J., \& Sullivan, P. (2012). Canadian curling coaches' use of psychological skills training. The sport psychologist, 26(1), 29-42.

Sheard, M., \& Golby, J. (2006). Effect of a psychological skills training program on swimming performance and positive psychological development. International journal of sport and exercise psychology, 4(2), 149-169.

Taheri, M., \& Irandoust, K. (2017). The effect of balance exercises and computerized cognitive training on psychomotor performance in elderly. Journal of Physical Therapy Science, 29(12), 2097-2099.

Williams, J. M., \& Krane, V. (2001). Psychological characteristics of peak performance. Applied sport psychology: Personal growth to peak performance, 4, 137-147.

Znazen, H., Slimani, M., Miarka, B., Butovskaya, M., Siala, H., Messaqud, T., \& Chamari, K. (2016). Mental skills comparison between elite sprint and endurance track and field runners according to their genetic polymorphism: a pilot Study. Journal of Sports Medicine and Physical Fitness, e-print. 